\title{
Legemiddelinteraksjoner og immunsuppresjon hos organtransplanterte
}

\begin{abstract}
Sammendrag
Bakgrunn. Immundempende legemidler brukes for å hindre avstøtning etter organtransplantasjon. De fleste av disse midlene har smale terapeutiske konsentrasjonsområder. Dette øker sannsynligheten for klinisk relevante legemiddelinteraksjoner. Vi gir her en oversikt over interaksjoner som kan ha betydning for den immundempende behandling.
\end{abstract}

Materiale og metode. Interaksjonsdata for immundempende legemidler ble fremskaffet ved et litteratursøk i PubMed. Artikler ble valgt ut fra klinisk relevans.

\section{Resultater. I litteraturen omtales} hovedsakelig farmakokinetiske interaksjoner. Kalsineurinhemmere (ciklosporin, takrolimus) og mTORhemmere (sirolimus, everolimus) er spesielt utsatt for påvirkning fra stoffer som hemmer eller induserer cytokrom P-450 (CYP) 3A4 og P-glykoprotein. Slike interaksjoner kan medføre at blodnivåene av de immundempende legemidlene endrer seg mer enn ti ganger. Også metylprednisolon og prednisolon kan påvirkes av stoffer som modulerer CYP3A4 og P-glykoprotein. Nivået av mykofenolat reduseres ved samtidig bruk av enkelte protonpumpehemmere, antibiotika og anionbindere samt av valproinsyre og rifampicin. Noen immundempende legemidler påvirker også hverandre: Ciklosporin øker nivået av mTOR-hemmerne og senker nivået av mykofenolat. Generelt vil den farmakologiske interaksjonsgraden variere mellom individer.

Fortolkning. Ved en forventet klinisk relevant legemiddelinteraksjon er hyppige konsentrasjonsmålinger av det aktuelle legemidlet et godt hjelpemiddel for individuell justering av den immundempende behandlingen. Forhåndskunnskap om legemiddelinteraksjoner kan dermed bidra til å forebygge uønskede endringer i den immundempende effekten.
Nils Tore Vethe

nils.tore.vethe@oslo-universitetssykehus.no Avdeling for medisinsk biokjemi

\section{Karsten Midtvedt}

Avdeling for organtransplantasjon

Oslo universitetssykehus

\section{Anders Åsberg}

Rune Amundsen

Farmasøytisk Institutt

Universitetet i Oslo

\section{Stein Bergan}

Avdeling for farmakologi

Oslo universitetssykehus og

Farmasøytisk institutt Universitetet i Oslo

Livslang behandling med immundempende legemidler er nødvendig etter organtransplantasjon for å forebygge avstøtningsepisoder og bevare transplantatet. Et vedlikeholdsregime består ofte av en kalsineurinhemmer (CNI ciklosporin eller takrolimus), prednisolon og mykofenolat. De nyere «mammalian target of rapamycin»-inhibitorene (mTORi), sirolimus og everolimus, kombineres også i enkelte tilfeller med ovenfornevnte legemidler.

I transplantasjonssammenheng er det etablert terapeutiske konsentrasjonsområder for CNI, mTORi og til dels for mykofenolat (1). Behandlingsprotokoller angir optimale legemiddelkonsentrasjoner i spesifikke tidsintervaller etter transplantasjon. Det vanligste når det gjelder CNI, mTORi og mykofenolat, er å måle konsentrasjonen i blod eller plasma helt i slutten av doseintervallet, like før neste dose inntas. Hyppige konsentrasjonsmålinger, spesielt i tidlig fase etter transplantasjonen, er nødvendig for å tilpasse doseringen hos den enkelte pasient.

En legemiddelinteraksjon innebærer at ett legemiddels effekt eller toksisitet endres som følge av samtidig bruk av et annet legemiddel (eller stoff). De fleste immundempende legemidlene har smale terapeutiske konsentrasjonsområder. Derfor vil deres effekt potensielt være sårbar for legemiddelinteraksjoner. I denne artikkelen gir vi en beskrivelse av legemiddelinteraksjoner som kan ha betydning for den kliniske effekten av immundempende behandling. Primært vil dette ha betydning etter organtransplantasjon, men det gjelder også ved bruk av disse legemidlene ved andre tilstander som stamcelletransplantasjon, revmatoid artritt, psoriasis og systemisk lupus erythematosus.

\section{Materiale og metode}

Grunnlaget for artikkelen er et litteratursøk i databasen PubMed og forfatternes vitenskapelige og kliniske erfaring vedrørende legemiddelinteraksjoner og immunsuppresjon. Referansene inkluderer studier i populasjoner av transplanterte pasienter, andre pasientgrupper og friske frivillige samt kasusrapporter og oversiktsartikler.

\section{Kalsineurinhemmere og mTOR-hemmere}

Ciklosporin og takrolimus hemmer fosfatasen kalsineurin og reduserer dermed produksjonen av interleukin-2, som er viktig for aktivering av T-lymfocytter (2). Sirolimus og everolimus hemmer kinaseaktiviteten til mTOR-kompleks 1 slik at proliferasjonen av aktiverte lymfocytter bremses (3).

Både CNI og mTORi metaboliseres i stor grad av cytokrom P-450 (CYP) 3A4 i tarm og lever (4). I tillegg transporteres de ut via efflukspumpen P-glykoprotein (P-gp), som blant annet finnes i tarm, lever og nyrer (5). Legemidler som hemmer CYP3A4 og/eller P-gp, reduserer metabolisme og utskilling av CNI og mTORi og vil dermed gi økt konsentrasjon av disse. På den annen side kan enkelte legemidler indusere mengden CYP3A4 og/eller P-gp via transkripsjonell aktivering, noe som resulterer i økt eliminasjon og følgende reduserte nivåer av CNI og mTORi. Substanser som hemmer eller induserer CYP3A4 og P-gp vil i mange tilfeller ha effekter på dem begge (6). Aktuelle hemmere og induktorer av CYP3A4 og P-gp er vist i tabell $1(4,6-21)$.

Kraftige interaksjoner er rapportert i forbindelse med peroral bruk av soppmidlene ketokonazol, flukonazol, itrakonazol, vorikonazol og posakonazol. Disse legemidlene hemmer CYP3A4, og enkelte hemmer også P-gp. Interaksjonen er raskt innsettende og

\section{Hovedbudskap}

- Immundempende legemidler hos transplanterte er svært utsatt for legemiddelinteraksjoner

- Unngå om mulig legemidler som kan påvirke effekten av immundempende midler hos transplanterte

- Tilrettelegg for individuell dosering ved å ha kunnskap om interaksjoner, og monitorer legemiddelnivået 
graden vil kunne være initialt økende, mens den ofte opphører en til to uker etter seponering $(4,22)$. Soppmidlene øker CNI-konsentrasjonen i blodet i gjennomsnitt $2-3$ ganger (4). Interaksjonsgraden varierer mellom individer og mellom de ulike azolforbindelsene, i tillegg er den doseavhengig (4). Ekstreme nivåøkninger av CNI og mTORi kan forekomme, spesielt ved bruk av vorikonazol, hvor det foreligger rapporter på 10-20 ganger økte nivåer av takrolimus hos enkeltindivider $(22,23)$. For sirolimus og everolimus kan man forvente 5-15 ganger økte nivåer dersom azoler tas i bruk $(4,24)$.

Antibiotikaene erytromycin og klaritromycin hemmer både CYP3A4 og P-gp $(6,8)$, og man bør utvise stor forsiktighet dersom disse makrolidene kombineres med CNI eller mTORi. Påpasselighet bør også utvises ved azitromycinbehandling, siden det her finnes rapporter på moderate økninger av nivåene av takrolimus og everolimus $(25,26)$.

Kalsiumantagonistene diltiazem og verapamil hemmer også CYP3A4 og P-gp og kan forårsake betydelig forhøyede konsentrasjoner av CNI og mTORi $(9,15-17)$. På en annen side kan enkelte kalsiumantagonister (f.eks. nifedipin) påvirke nyrefunksjonen positivt hos nyretransplanterte som har høyt blodtrykk og bruker ciklosporin (27). Dette skyldes at kalsiumantagonistens vasodilaterende effekt motvirker den vasokonstriksjonen i nyrene som ciklosporin forårsaker (21).

Ved samtidig bruk av CNI og mTORi kan enkelte av disse legemidlene interagere med hverandre via CYP3A4 og P-gp. Ciklosporin gir 2-3 ganger økte nivåer av sirolimus og everolimus når legemidlene kombineres peroralt $(10,19)$. Det er også holdepunkter for at mTORi forsterker de nefrotoksiske effektene av CNI. Denne interaksjonen forekommer tilsynelatende uten direkte relasjon til systemiske legemiddelnivåer. En teori som er underbygd av in vitro-modeller, er at mTORi øker den lokale eksponeringen av CNI i nyrevev. Dette kan skyldes at legemidlene konkurrerer om å bli pumpet ut av cellene via P-gp $(21,28)$.

\section{Mykofenolat}

Mykofenolat er tilgjengelig som mykofenolatmofetil og som enterodrasjert mykofenolatnatrium. Dette legemidlet bremser proliferasjonen av aktiverte lymfocytter ved å hemme syntesen av (deoksy)guaninnukleotider (29). Aktuelle legemiddelinteraksjoner for mykofenolat er oppsummert i tabell 2 (30-43).

Mykofenolat gjennomgår enterohepatisk sirkulasjon (39). Den inaktive hovedmetabolitten mykofenolatglukuronid skilles ut i gallen og spaltes av bakterielle glukuronidaser i tarmen slik at mykofenolat kan tas opp på nytt. Ciklosporin, gallesyrebindere og enkelte antibiotika reduserer nivået av mykofenolat ved å hindre legemidlets enterohepatiske sirkulasjon (30-32, 39, 41-43).

Protonpumpehemmerne lansoprazol og pantoprazol reduserer mykofenolats biotil-
Tabell 1 Interaksjoner med kalsineurinhemmere, mTOR-hemmere og kortikosteroider. Høy grad av forsiktighet må utvises i forbindelse med interaksjonene. Tabellen gir ikke en fullstendig oversikt over alle relevante interaksjoner. Referanser i parentes
Legemidler som øker konsentrasjonen av ciklosporin, takrolimus

sirolimus, everolimus

metylprednisolon

(hemmere av CYP3A4 og/eller P-gp)

Flukonazol, itrakonazol, ketokonazol,

posakonazol, vorikonazol $(4,6-12)$

Erytromycin, klaritromycin $(6-10,13,14)$

Diltiazem, verapamil (6-10, 15-18)

Indinavir, ritonavir $(6,8)$

Grapefruktjuice 2 (8, 9)

Ciklosporin $\Rightarrow \varnothing k t$ systemisk nivå av sirolimus og everolimus $(10,19)$

Sirolimus, everolimus $\Rightarrow \varnothing k t$ lokalt nivå

av ciklosporin og takrolimus i nyrevev

kan gi økt nefrotoksisitet (21)

1 Naturlegemiddel

${ }^{2}$ Næringsmiddel

${ }^{3}$ Ikke relatert til induksjon av CYP3A4 eller P-gP

gjengelighet (33-35). Dette er dokumentert ved bruk av mykofenolatmofetil. Interaksjonen kan skyldes redusert absorpsjon i relasjon til protonpumpehemmernes effekt på $\mathrm{pH}$ i ventrikkelen. En nylig publisert studie indikerer at pantoprazol ikke påvirker mykofenolat dersom enterodrasjert mykofenolatnatrium brukes (44). Også antacider (aluminium-/ magnesiumhydroksid) kan føre til noe redusert absorpsjon av mykofenolat (45).

Kasusrapporter av nyretransplanterte indikerer at epilepsimidlet valproinsyre reduserer totalkonsentrasjonen av mykofenolat
Legemidler som reduserer konsentrasjonen av ciklosporin, takrolimus

sirolimus, everolimus

metylprednisolon, prednisolon

(induktorer av CYP3A4 og/eller P-gp)

Fenobarbital, fenytoin, karbamazepin (7)

Rifampicin $(6,7,10)$

Johannesurt (Hypericum perforatum) 16 )

Orlistat $\Rightarrow$ redusert absorpsjon og systemisk nivå av ciklosporin ${ }^{3}(20)$
(38). En årsakshypotese er at valproinsyre fortrenger mykofenolat fra albumin og dermed gjør mer mykofenolat tilgjengelig for metabolisme. Det er ikke kjent hvordan det frie (albuminubundne) konsentrasjonsnivået av mykofenolat påvirkes under interaksjonen.

Det er også rapportert at tuberkulostatisk behandling med rifampicin medfører redusert mykofenolatnivå $(36,37)$. Rifampicin induserer uttrykket av glukuronosyltransferaser slik at glukuronideringen av mykofenolat øker $(36,46)$.
Tabell 2 Interaksjoner med mykofenolat. Høy grad av forsiktighet må utvises i forbindelse med interaksjonene. Tabellen gir ikke en fullstendig oversikt over alle relevante interaksjoner. De oppgitte interaksjonene er rapportert ved bruk av mykofenolatmofetil. Enterohepatisk sirkulasjon $(E H C)$, arealet under konsentrasjon-tids-kurven (AUC), konsentrasjon like før neste dose $\left(C_{0}\right)$, maksimumskonsentrasjon $\left(\mathrm{C}_{\text {maks }}\right)$. Referanser i parentes

\begin{tabular}{|c|c|c|}
\hline Interagerende legemidler & Mekanisme & $\begin{array}{l}\text { Mykofenolat } \\
\text { Total plasmakonsentrasjon }\end{array}$ \\
\hline Ciklosporin & Redusert EHC & AUC $\downarrow 30-40 \%, C_{0} \downarrow$ ca. $60 \%(30-32)$ \\
\hline Lansoprazol, pantoprazol & $\begin{array}{l}\text { Assosiert med redusert } \\
\text { absorpsjon }\end{array}$ & AUC $\downarrow 30-40 \%, C_{\text {maks }} \downarrow 30-80 \%(33-35)$ \\
\hline Rifampicin & $\emptyset k t$ metabolisme & $\begin{array}{l}\text { AUC } \downarrow \text { ca. } 20 \%(36) \\
\text { Kasus, } n=1: \text { AUC } \downarrow \text { ca. } 70 \% \text { (37) }\end{array}$ \\
\hline Valproinsyre & $\begin{array}{l}\text { Mulig fortrengning } \\
\text { fra albumin og følgende } \\
\text { øt eliminasjon }\end{array}$ & Kasus, $n=3:$ AUC $\downarrow 30-60 \%$ (38) \\
\hline $\begin{array}{l}\text { Gallesyrebindere } \\
\text { som kolestyramin }\end{array}$ & Redusert EHC & AUC $\downarrow 10-60 \%$ (39) \\
\hline Sevelamer & $\begin{array}{l}\text { Assosiert med redusert } \\
\text { absorpsjon }\end{array}$ & AUC $\downarrow$ ca. $25 \%, C_{\text {maks }} \downarrow$ ca. $30 \%(40)$ \\
\hline $\begin{array}{l}\text { Metronidazol, tobramycin } \\
\text { +cefuroksim }\end{array}$ & Redusert EHC & AUC $\downarrow 20-30 \%(41,42)$ \\
\hline Ciprofloksacin & Redusert EHC & Kasus, $n=1:$ AUC $\downarrow$ ca. $60 \%$ (43) \\
\hline
\end{tabular}




\section{Kortikosteroider}

Prednisolon og metylprednisolon virker immundempende ved å regulere genuttrykket av en rekke faktorer (cytokiner, kjemokiner m.m.) som kontrollerer immuncellenes status (47).

Hemmere av CYP3A4 og/eller P-gp vil kunne øke plasmakonsentrasjonen av metylprednisolon. Prednisolon blir tilsynelatende i mindre grad påvirket av slike hemmere $(11-14,18)$

Legemidler som induserer mengden CYP3A4 og/eller P-gp, har potensial til å redusere plasmakonsentrasjonen av både prednisolon og metylprednisolon. Effekten er imidlertid kraftigst på metylprednisolon (48).

Aktuelle hemmere og induktorer av CYP3A4 og/eller P-gp fremgår av tabell 1.

\section{Vurdering og håndtering av interaksjoner}

Når er en legemiddelinteraksjon klinisk relevant? Hva kan man gjøre for å minimere den potensielle risikoen knyttet til en legemiddelinteraksjon? For å kunne forutsi om en farmakokinetisk interaksjon vil innebære risiko for terapisvikt eller toksisitet må man ha kunnskap om den forventede størrelsen på endringen av legemiddelnivået. Samtidig må man kunne anslå hvor stor nivåendring som skal til for å gi økt risiko hos den aktuelle pasienten. Da må bredden på det terapeutiske området være kjent og man må vite hvor i området pasientens legemiddelnivå ligger før interaksjonen inntreffer. Det er vanlig å anta at legemiddelnivåer utenfor det dokumenterte terapeutiske området medfører forhøyet risiko, selv om under-/overskridelsesgrad og individuell ømfintlighet sannsynligvis også spiller inn.

De prosentvise endringene av legemiddelnivåer som oppgis i litteraturen, kan være en god pekepinn på hva man kan forvente ved spesifikke interaksjoner. Man bør likevel være oppmerksom på at man da gjerne forholder seg til gjennomsnittlig endring i en studiepopulasjon (ofte friske frivillige). Det kan også være data fra kasusrapporter som i flere tilfeller er basert på ekstreme observasjoner. Man bør ta høyde for at interaksjonsgraden kan være doseavhengig og at den varierer mellom individer. Vår skjønnsmessige vurdering er at man bør være oppmerksom på farmakokinetiske interaksjoner som kan forårsake mer enn ca. $25 \%$ endring av legemiddelnivået. Slike endringer vil ofte medføre legemiddelkonsentrasjoner utenfor optimalt område og dermed øke sannsynligheten for klinisk relevant under- eller overeksponering. Ved større endringer bør man vurdere tiltak for å minimere effekten av interaksjonene. Det er likevel viktig å se observerte nivåendringer i sammenheng med den anvendte målemetodens presisjon og pasientens farmakokinetiske dag-til-dag-variasjon.

Når et legemiddel introduseres, seponeres eller dosejusteres betydelig, bør man vurdere om dette kan påvirke den etablerte immundempende behandlingen. Dersom en klinisk relevant interaksjon forventes å inntreffe, kan man se etter likeverdige behandlingsalternativer uten kjent interaksjon. Dersom interaksjonen er uunngåelig, vil det i tillegg til å overvåke det kliniske bildet også være hensiktsmessig å følge ekstra nøye med på blodnivået av det aktuelle immundempende legemidlet. Hyppig monitorering av legemiddelnivået før, under og etter interaksjonsperioden kan brukes til å vurdere behovet for dosejusteringer. I tillegg kan det i enkelte situasjoner være aktuelt å justere dosen av det immundempende legemidlet parallelt med legemiddelintervensjonen. Det er da viktig å ha detaljert forhåndskunnskap om forventet interaksjonsgrad og sørge for tett overvåking av legemiddelnivået hos den aktuelle pasienten. Som regel kan man anta proporsjonalitet mellom dose og blodkonsentrasjon hos den enkelte pasient. Eksempelvis vil en interaksjon som medfører doblet legemiddelnivå kunne korrigeres med en halvering av dosen. Supplementære strategier kan være å gjøre doseringen av de interagerende legemidlene atskilt $i$ tid eller anvende en alternativ administreringsvei (f.eks. intravenøs administrering dersom legemiddelinteraksjonen er relatert til absorpsjon fra tarm).

Uavhengig av hvilken strategi som velges for å minimere interaksjonseffekten, og forutsatt at analyse av aktuelt immundempende legemiddel er teknisk tilgjengelig, bør man utføre hyppige målinger av legemiddelnivået og eventuelt gjøre nødvendige dosejusteringer.

\section{Nils Tore Vethe (f. 1978)}

er cand.pharm. og ph.d. i farmakologi. Han er forsker ved Avdeling for medisinsk biokjemi,

Oslo universitetssykehus.

Oppgitte interessekonflikter: Forfatteren har fått forelesningshonorar fra Novartis.

\section{Karsten Midtvedt (f. 1957)}

er overlege på nyreseksjonen ved Oslo universitetssykehus og arbeider med og forsker på oppfølging av nyretransplanterte pasienter. Ingen oppgitte interessekonflikter.

\section{Anders Åsberg (f. 1968)}

er cand.pharm., dr.scient. og professor i farmakologi ved Farmasøytisk institutt. Ingen oppgitte interessekonflikter.

\section{Rune Amundsen (f. 1977)}

er cand.pharm. og stipendiat ved Farmasøytisk institutt. For tiden er han høyskolelektor ved Høgskolen i Oslo.

Ingen oppgitte interessekonflikter.

\section{Stein Bergan (f. 1954)}

er cand.pharm., dr.philos. og forsker og profes sor II ved Avdeling for farmakologi og Farmasøytisk institutt. Han har fagansvar for farma kologisk analysevirksomhet, spesielt immunsuppresjon knyttet til transplantasjon og cytostatika, og er leder av en forskningsgruppe med tema farmakokinetikk, dynamikk og genetikk hos immunsuppressiver

Ingen oppgitte interessekonflikter.
Litteratur

1. Wallemacq PE. Therapeutic monitoring of immuno suppressant drugs. Where are we? Clin Chem Lab Med 2004; 42: 1204-11.

2. Kapturczak MH, Meier-Kriesche HU, Kaplan B. Pharmacology of calcineurin antagonists. Transplant Proc 2004; 36 (suppl 2): 25S-32S

3. Thomson AW, Turnquist HR, Raimondi G. Immunoregulatory functions of mTOR inhibition. Nat Rev Immunol 2009. 9. 324-37.

4. Saad AH, DePestel DD, Carver PL. Factors influencing the magnitude and clinical significance of drug interactions between azole antifungals and select immunosuppressants. Pharmacotherapy 2006: 26: 1730-44

5. Cascorbi I. P-glycoprotein: tissue distribution, substrates, and functional consequences of genetic variations. Handb Exp Pharmacol 2011; 201 $261-83$

6. Marchetti S, Mazzanti R, Beijnen JH et al. Concise review: clinical relevance of drug drug and herb drug interactions mediated by the $\mathrm{ABC}$ transporter ABCB1 (MDR1, P-glycoprotein). Oncologist 2007; 12: $927-41$

7. Liu YT, Hao HP, Liu CX et al. Drugs as CYP3A probes, inducers, and inhibitors. Drug Metab Rev 2007: 39: 699-721.

8. Dresser GK, Spence JD, Bailey DG. Pharmacokin etic-pharmacodynamic consequences and clinical relevance of cytochrome P450 3A4 inhibition. Clin Pharmacokinet 2000; 38: 41-57.

9. Martin JE, Daoud AJ, Schroeder TJ et al. The clinical and economic potential of cyclosporin drug interactions. Pharmacoeconomics 1999; 15 317-37.

10. Zimmerman JJ. Exposure-response relationships and drug interactions of sirolimus. AAPS J 2004; 6: e28.

11. Kandrotas RJ, Slaughter RL, Brass C et al. Ketoconazole effects on methylprednisolone disposition and their joint suppression of endogenous cortisol. Clin Pharmacol Ther 1987: 42: 465-70.

12. Lebrun-Vignes B, Archer VC, Diquet B et al. Effect of itraconazole on the pharmacokinetics of predni solone and methylprednisolone and cortisol secretion in healthy subjects. Br J Clin Pharmacol 2001: 51: 443-50.

13. Fost DA, Leung DY, Martin RJ et al. Inhibition of methylprednisolone elimination in the presence of clarithromycin therapy. J Allergy Clin Immunol 1999: 103: 1031-5.

14. LaForce CF. Szefler SJ, Miller MF et al. Inhibition of methylprednisolone elimination in the presence of erythromycin therapy. J Allergy Clin Immunol 1983; $72: 34-9$

15. Böttiger Y, Säwe J, Brattström $C$ et al. Pharmacokinetic interaction between single oral doses of diltiazem and sirolimus in healthy volunteers. Clin Pharmacol Ther 2001; 69: 32-40

16. Jones TE, Morris RG. Pharmacokinetic interaction between tacrolimus and diltiazem: dose-response relationship in kidney and liver transplant recipients. Clin Pharmacokinet 2002; 41: 381-8.

17. Kovarik JM, Beyer D, Bizot MN et al. Pharmacokinetic interaction between verapamil and everolimus in healthy subjects. Br J Clin Pharmacol 2005; 60: 434-7.

18. Varis T, Backman JT, Kivistö KT et al. Diltiazem and mibefradil increase the plasma concentrations and greatly enhance the adrenal-suppressant effect of oral methylprednisolone. Clin Phar macol Ther 2000; 67: 215-21.

19. Brandhorst $G$, Tenderich $G$, Zittermann A et al. Everolimus exposure in cardiac transplant recipients is influenced by concomitant calcineurin inhibitor. Ther Drug Monit 2008; 30: 113-6.

20. Zhi J, Moore R, Kanitra L et al. Pharmacokinetic evaluation of the possible interaction between selected concomitant medications and orlistat at steady state in healthy subjects. J Clin Pharmacol 2002; 42: $1011-9$

21. Naesens M, Kuypers DR, Sarwal M. Calcineurin inhibitor nephrotoxicity. Clin J Am Soc Nephrol 2009; 4: 481-508.

22. Venkataramanan R, Zang S, Gayowski T et al. Voriconazole inhibition of the metabolism of tacrolimus in a liver transplant recipient and in human liver microsomes. Antimicrob Agents Chemother 2002; 46: 3091-3. 
23. Capone D, Tarantino G, Gentile A et al. Effects of voriconazole on tacrolimus metabolism in a kidney transplant recipient. J Clin Pharm Ther 2010; 35: $121-4$

24. Kovarik JM, Beyer D, Bizot MN et al. Blood concentrations of everolimus are markedly increased by ketoconazole. J Clin Pharmacol 2005; 45 514-8.

25. Kovarik JM, Hsu CH, McMahon L et al. Population pharmacokinetics of everolimus in de novo renal transplant patients: impact of ethnicity and comedications. Clin Pharmacol Ther 2001; 70: 247-54.

26. Mori T, Aisa Y, Nakazato T et al. Tacrolimus-azithromycin interaction in a recipient of allogeneic bone marrow transplantation. Transpl Int 2005; 18: $757-8$

27. Midtvedt K, Hartmann A, Foss A et al. Sustained improvement of renal graft function for two years in hypertensive renal transplant recipients treated with nifedipine as compared to lisinopril. Transplantation 2001; 72: 1787-92.

28. Anglicheau D, Pallet N, Rabant M et al. Role of $\mathrm{P}$-glycoprotein in cyclosporine cytotoxicity in the cyclosporine-sirolimus interaction. Kidney Int 2006; 70: 1019-25.

29. Allison AC, Eugui EM. Mechanisms of action of mycophenolate mofetil in preventing acute and chronic allograft rejection. Transplantation 2005; 80 (suppl): S181-90

30. Mandla R, Midtvedt K, Line PD et al. Mycophenolic acid clinical pharmacokinetics influenced by a cyclosporine $\mathrm{C} 2$ based immunosuppressive regimen in renal allograft recipients. Transpl Int 2006; 19: $44-53$

31. Picard N, Prémaud A, Rousseau A et al. A comparison of the effect of ciclosporin and sirolimus on the pharmokinetics of mycophenolate in renal transplant patients. Br J Clin Pharmacol 2006; 62: 477-84.

32. Zucker K, Rosen A, Tsaroucha A et al. Unexpected augmentation of mycophenolic acid pharmaco- kinetics in renal transplant patients receiving tacrolimus and mycophenolate mofetil in combination therapy, and analogous in vitro findings. Transpl Immunol 1997; 5: 225-32.

33. Doesch AO, Mueller S, Konstandin M et al. Proton pump inhibitor co-medication reduces active drug exposure in heart transplant recipients receiving mycophenolate mofetil. Transplant Proc 2010; 42: 4243-6.

34. Kofler S, Deutsch MA, Bigdeli AK et al. Proton pump inhibitor co-medication reduces mycophenolate acid drug exposure in heart transplant recipients. J Heart Lung Transplant 2009; 28: 605-11.

35. Miura M, Satoh S, Inoue K et al. Influence of lansoprazole and rabeprazole on mycophenolic acid pharmacokinetics one year after renal transplantation. Ther Drug Monit 2008; 30: 46-51.

36. Naesens M, Kuypers DR, Streit F et al. Rifampin induces alterations in mycophenolic acid glucuronidation and elimination: implications for drug exposure in renal allograft recipients. Clin Pharmacol Ther 2006; 80: 509-21.

37. Kuypers DR, Verleden G, Naesens M et al. Drug interaction between mycophenolate mofetil and rifampin: possible induction of uridine diphosphate-glucuronosyltransferase. Clin Pharmacol Ther 2005; 78: 81-8.

38. Annapandian VM, John GT, Mathew BS et al. Pharmacokinetic interaction between sodium valproate and mycophenolate in renal allograft recipients. Transplantation 2009; 88: 1143-5.

39. Bullingham RE, Nicholls AJ, Kamm BR. Clinical pharmacokinetics of mycophenolate mofetil. Clin Pharmacokinet 1998; 34: 429-55.

40. Pieper AK, Buhle F, Bauer S et al. The effect of sevelamer on the pharmacokinetics of cyclosporin A and mycophenolate mofetil after renal transplantation. Nephrol Dial Transplant 2004; 19. 2630-3.

41. Naderer OJ, Dupuis RE, Heinzen EL et al. The influence of norfloxacin and metronidazole on the disposition of mycophenolate mofetil. J Clin Pharmacol 2005; 45: 219-26.

42. Schmidt LE, Rasmussen A, Nørrelykke MR et al. The effect of selective bowel decontamination on the pharmacokinetics of mycophenolate mofetil in liver transplant recipients. Liver Transpl 2001; 7: 739-42.

43. Goutelle S, Mialou V, Gouraud A et al. Probable drug interaction between intravenous ciprofloxacin and mycophenolate mofetil in a bone marrow transplant recipient. Pharmacotherapy 2011; 31: 37e-40e.

44. Kofler S, Wolf $\mathrm{C}$, Shvets $\mathrm{N}$ et al. The proton pump inhibitor pantoprazole and its interaction with enteric-coated mycophenolate sodium in transplant recipients. J Heart Lung Transplant 2011; 30: $565-71$.

45. Bullingham R, Shah J, Goldblum R et al. Effects of food and antacid on the pharmacokinetics of single doses of mycophenolate mofetil in rheumatoid arthritis patients. Br J Clin Pharmacol 1996; 41: 513-6.

46. Rae JM, Johnson MD, Lippman ME et al. Rifampin is a selective, pleiotropic inducer of drug metabolism genes in human hepatocytes: studies with cDNA and oligonucleotide expression arrays. J Pharmacol Exp Ther 2001; 299: 849-57.

47. Czock D, Keller F, Rasche FM et al. Pharmacokinetics and pharmacodynamics of systemically administered glucocorticoids. Clin Pharmacokinet 2005; 44: 61-98.

48. Bartoszek M, Brenner AM, Szefler SJ. Prednisolone and methylprednisolone kinetics in children. Clin Pharmacol Ther 1987; 42: 424-32.

Mottatt 27.1. 2011, første revisjon innsendt 8.4. 2011, godkjent 16.6. 2011. Medisinsk redaktør Trine B. Haugen. 